\title{
UNCERTAINTY OF FLOW REGIME CHARACTERISTICS OF RIVERS IN EUROPE
}

\author{
DARIUSZ WRZESIŃSKI \\ Institute of Physical Geography and Environmental Planning, Adam Mickiewicz University in Poznań, Poland \\ Manuscript received: September 20, 2012 \\ Revised version: February 13, 2013
}

\begin{abstract}
WrZESIŃSKi D., 2013. Uncertainty of flow regime characteristics of rivers in Europe. Quaestiones Geographicae 32(1), Bogucki Wydawnictwo Naukowe, Poznań, pp. 43-53. 1 table, 5 figs. DOI 10.2478/quageo-2013-0006, ISSN 0137$477 X$.

ABSTRACT. The aim of the paper is to describe spatial differences in the uncertainty of features of the flow regimes of rivers in Europe on the basis of measures whose methodological assumptions derive from Shannon's information entropy theory (1948). They included: the entropy of monthly flow volumes, the entropy of the flow distribution over time, and the entropy of maximum and minimum monthly flows. An analysis was made of monthly flow series for the years 1951-1990 from 510 gauging stations located on 369 rivers in Europe. It allowed a quantitative determination of the degree of uncertainty of the four regime characteristics, indirectly establishing the predictability, regularity and stability of their appearance and their spatial variability. In the procedure of identification of spatial differences among rivers concerning the uncertainty of their flow regime features, use was made of local indices of spatial dependence. On application of LISA (Local Indicators of Spatial Association) based on Moran's local $I_{i}$ statistic, a typology of rivers was obtained in terms of the kind and statistical significance of spatial associations involving the uncertainty of the flow regime variables in question.
\end{abstract}

KEYWORDS: river regime; Europe, entropy; local spatial association

Dariusz Wrzesinski, Department of Hydrology and Water Management, Institute of Physical Geography and Environmental Planning, Adam Mickiewicz University, ul. Dzięgielowa 27, 61-680 Poznań, Poland, e-mail:darwrze@amu.edu.pl

\section{Introduction}

An important stream of present-day research on environmental changes is the detection of change in the hydrological cycle, both at the global scale as well as the regional and local ones. An especially significant issue is the seasonality of river flow, availability and magnitude of water resources, and their permanence and predictability, i.e. the stability of the hydrological regime, not only from a scientific perspective, but also be- cause of the economic and social consequences of its destabilisation.

Regular variations in all river-related phenomena are defined by the river's hydrological regime. It determines the state and responses of the river system in relation to the climatic system and the physical-geographic features of the river basin. Among studies of the effect of changes in the climatic conditions on the geographical environment, including water resources, there is a growing number of those dealing with climat- 
ic factors underlying changes in the seasonality of river flows and regimes (e.g. Krasovskaia \& Gottschalk 1992, Krasovskaia 1995, 1996, Krasovskaia \& Sælthun 1997, Wilson et al. 2012). Because of global warming, one can observe periodic variations in river discharges accompanied by a growing interest of scholars in the transformation of river regimes (e.g. Westmacott \& Burn 1997, Middelkoop et al. 2001). Worth noting are new methodological approaches and regional syntheses (e.g. Arnell 1999a, Krasovskaia et al. 1999, Shorthouse \& Arnell 1999, Gutry-Korycka \& Rotnicka 1998, Wrzesiński 2008, 2010, Wrzesiński \& Paluszkiewicz 2011). An assessment of the effect of changes in and variability of the climate on the hydrological regimes of rivers in Europe was presented by Arnell (1999b). An interesting survey of methods used so far to establish climatic determinants of changes in the flow regime of rivers and their critical appraisal is offered by Bower et al. (2004).

Because of the present-day changes in climatic conditions and the marked human impact on water resources, an important issue is the understanding of the multi-year dynamics or stability of the flow regime. In this context, the flow regime is a useful tool in identifying spatial and temporal variations in the magnitude and seasonality of flow, and in anticipating present and future water deficits. The purpose of this paper is to propose and verify the usefulness of a few measures of regime features derived from Shannon's information entropy theory (1948) in assessing the stability and uncertainty of the flow regimes of European rivers.

A detailed analysis of the applications of information entropy in hydrological research was presented by Singh (1997). Entropy is usually employed as a measure of uncertainty, e.g. of hydrological simulation models (Amorocho \& Espildora 1973, Chapman 1986), or the occurrence and distribution of precipitation over time (Maruyama \& Kawachi 1998). Rainfall entropy has served to assess potential water resources at a regional scale in Japan (Kawachi et al. 2001) and at a global scale (Maruyama et al. 2005). Krasovskaia $(1995,1997)$ used entropy to make a typology of river flow regimes, and Barberis et al. (2003), to assess regime stability as a measure of the hydrological similarity of catchments. En- tropy as a measure of expected information has been employed, e.g., in a study of the precipitation-runoff relation (Krstanovic \& Singh 1992). The maximum entropy principle has found application, e.g., in an analysis of the frequency of hydrological variables (Sonuga 1972, 1976, Dalezios \& Tyraskis 1989, Koutsoyiannis 2005a, 2005b).

To calculate rainfall entropy, Maruyama et al. (2005) proposed two measures of entropy: of the intensity (magnitude) of precipitation (intensity entropy, IE) and of the distribution of precipitation over time (apportionment entropy, AE). In turn, Barberis et al. (2003) assessed regime stability as a measure of the hydrological similarity of catchments using the entropy of maximum and minimum monthly flows. They also suggested the possibility of using entropy to construct a new index for the classification of river regimes based on the popular monthly flow coefficient (the Pardè coefficient).

\section{Study area and input data}

The aim of this research and the tasks it involved required the accumulation and selection of a suitable dataset that would satisfy several preliminary conditions. For example, it had to represent a possibly wide spectrum of river flow determinants, allow a comparison, interpolation and spatial extrapolation of the results obtained, and ensure reliability and temporal uniformity of the hydrometeorological data.

In hydrological research, an important issue is the length of the series of measurement data under analysis, their reliability, and representativeness. The series sought are usually ones that are long, uniform and synchronous. In studies of the spatial structure of a phenomenon it is sometimes better to limit the length of a series in favour of a greater density of objects offering synchronous source material. Because of the spatial aspect of the analysis and the statistical approaches employed, the scope of the present work required the gathering of a great number of objects with possibly the longest, most uniform and synchronous series of data. The objects had to be distributed uniformly across space and represent areas with a diversity of environmental conditions. 


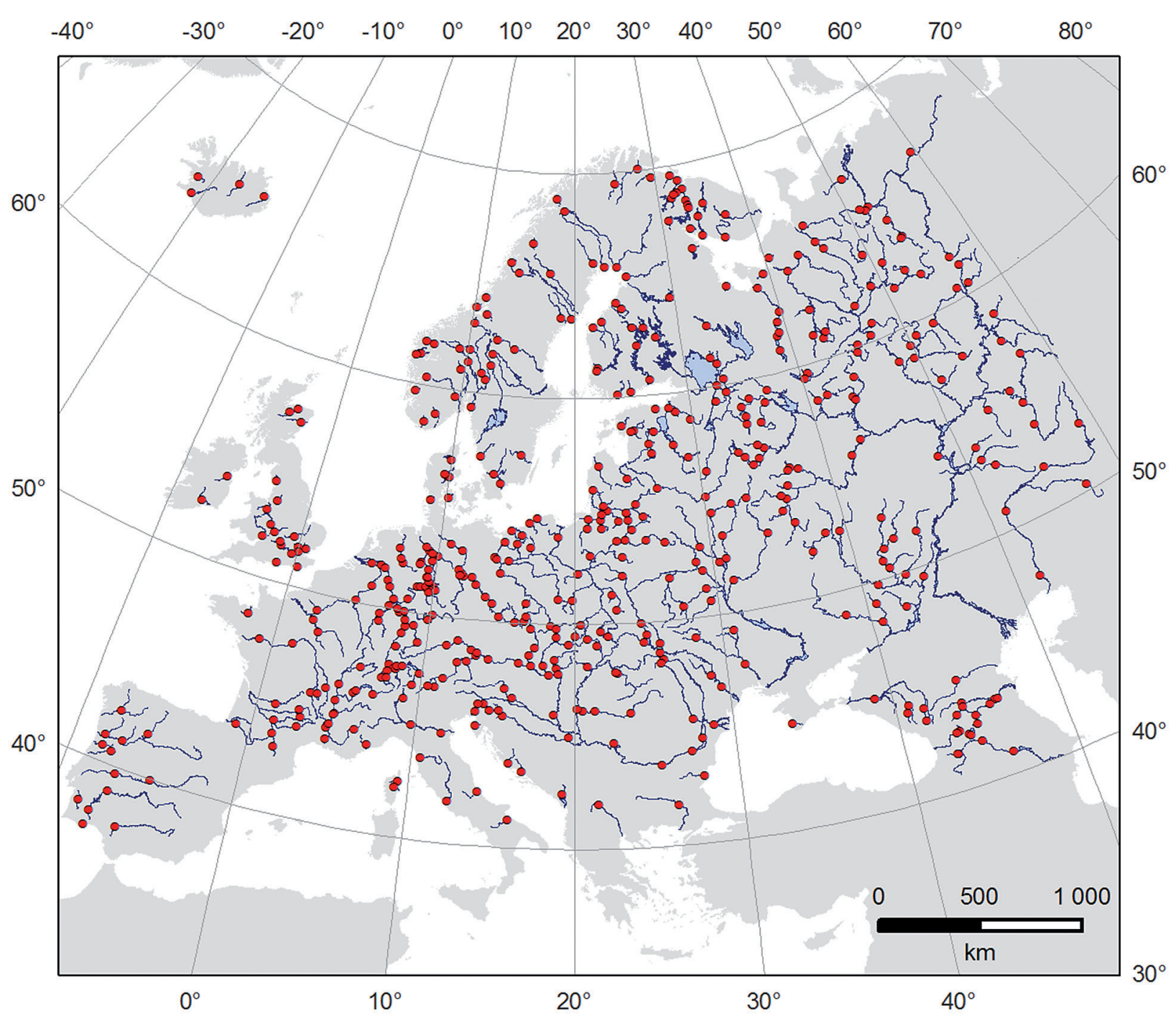

Fig. 1. Location of the river gauging stations.

Data series of mean monthly flows from 510 gauging stations located on 369 European rivers with natural or quasi-natural streamflow patterns was used (Fig. 1). Spanning the period 1951-1990 were used. The data came from the following sources: the Global Runoff Data Centre, HYDRO banque nationale de données pour l'hydrométrie et l'hydrologie (France), Hydrometeorological Center of Belarus, Institute of Meteorology and Water Management (Poland), National River Flow Archive (UK), Sistema Nacional de Informaçao de Recursos Hidricos (Portugal), and UNESCO's International Hydrological Programme.

A preliminary analysis of the source material consisted in checking the uniformity of the series of data with the help of Alexandersson's (1986) test. The decided majority of rivers chosen for study have small basins. Those under $5,000 \mathrm{~km}^{2}$ in area constituted $68 \%$ of the population, and those under $1000 \mathrm{~km}^{2}, 27 \%$. The remaining 32\% were streams with basins of more than $5,000 \mathrm{~km}^{2}$. Only a mere $4 \%$ of the analysed rivers have basins exceeding $100,000 \mathrm{~km}^{2}$.

\section{Methods}

In Shannon's information entropy theory (1948), entropy $(\mathrm{H})$ is the mean amount of information per sign symbolising an event from a set. Events in this set have a probability of occurrence assigned to them: 


$$
H=-\sum_{i=1}^{n} p_{i} \log _{r} p_{i}
$$

where: $p_{i}$ - the probability of occurrence of a concrete event, $n$ - the number of possible events, and $r$ - the base of the logarithm.

Since the amount of information is the logarithm of the probability of an event (message), the unit in which the information is calculated depends on the choice of the logarithmic base. If $r=10$, the unit is a dit (Hartley), if $r=e$ (the base of a natural logarithm), a nit (nat), and if $r=2$, a bit (binary digit).

Entropy as one of the measures of the uncertainty or disorder of a random variable can be calculated using Shannon's information entropy theory if the probability distribution function is given for the variable. According to the theory, the uncertainty of the variable, or the uncertainty of its probability distribution, is the negative expected value of the logarithm of its density distribution function. Entropy assumes a maximum value when the probability distribution is uniform, and approaches zero when a value of the variable has a probability of one.

To quantify deviations from a frequency distribution, use is usually made of variance, but entropy is more powerful and general (Maruyama et al. 2005). As is well known (Kagan et al. 1973), if the entropy of a random variable is maximised under the constraint that the variance and the mean are known for a set of values of the variable, the probability distribution function for the set is reduced to a normal distribution. This implies that the use of variance is limited to cases when the distribution is normal. Entropy, however, can be applied to any type of distribution, whether or not known a priori.

In this study, entropy theory was employed in an analysis of monthly flow series to quantify the uncertainty (disorder) in those data. Use was made of four measures allowing an assessment of the uncertainty of flow regime characteristics: the entropy of the flow volume, the entropy of the flow distribution over time, and the entropy of maximum and minimum flows (Wrzesiński 2010).

\subsection{Entropy of the flow volume}

Following the methodological approach proposed by Maruyama et al. (2005), formula (1) was used to determine the flow volume entropy $\left(E_{H}\right)$ for selected river gauging stations. The monthly flow is treated as the random variable, and $p_{i}$ as the probability of its occurrence in a flow series. Probabilities $p_{i}$ for individual gauging stations were expressed in a discrete form, accommodating all monthly flow figures and their probabilities. The flow volume entropy was calculated in the following stages:

- accumulation of a data set: monthly flow volumes from the multi-year period under analysis for the river gauging stations in question, with a population size of $N=12 \times m(m-$ the number of year),

- division of the data set into $n$ equal class intervals.

- calculation of the size $f_{i}$ of each class $i$ to make a table of the size distribution $\left\{f_{i}\right\}$,

- estimation of the probability $p_{i}=f_{i} / \mathrm{N}$ for the entire range of monthly flows in each class $i$, and

- calculation of entropy $E_{H}$ from the formula:

$$
E_{H}=-\sum_{i=1}^{n}\left(\frac{f_{i}}{N}\right) \log _{2}\left(\frac{f_{i}}{N}\right)
$$

where $n$ is the number of classes and $f_{i}$ is the size of class $i$. If the base 2 is used, the unit of entropy $E_{H}$ we obtain is a "bit".

Thus defined, the entropy of the flow volume $\left(E_{H}\right)$ assumes values from the interval $0 \leq E_{H}<$ $\infty$ and can be treated as a measure of the uncertainty of the magnitude of monthly flows. The lower the entropy, the lower the uncertainty of the variables; the higher the entropy, the greater the disorder of the variables and the lower their certainty.

\subsection{Entropy of the flow distribution over time}

The entropy of the flow distribution over time was defined by analogy to the entropy of precipitation distribution proposed by Maruyama et al. (2005). Assuming $r_{i}$ to be the monthly flow in the 
$i$-th month of the year, the annual flow $R$ can be expressed as the sum of $r_{i^{\prime}}$ from $i=1$ to 12 :

$$
R=\sum_{i=1}^{12} r_{i}
$$

In this case the probability $p_{i}$ can be estimated as the $r_{i} / R$ ratio. By employing information entropy, we obtain a measure of disorder in the distribution of monthly flows over the year $\left(E_{R}\right)$ which can be written as:

$$
E_{R}=-\sum_{i=1}^{12}\left(r_{i} / R\right) \log _{2}\left(r_{i} / R\right)
$$

As in the case of the flow volume entropy $\left(E_{H}\right)$, the unit of the apportionment entropy $\left(E_{R}\right)$ is the "bit" again. Its values are contained in the interval from 0 to $\log _{2} 12$, with the maximum $\left(E_{R}\right.$ $=\log _{2} 12$ ) attained when the annual flow is distributed evenly over all the months of the year $\left(p 1=p 2=p 3=\ldots p_{n}=1 / n\right)$. In turn, when the entire annual flow falls on a single month, the apportionment entropy assumes its minimum value $\left(E_{R}=0\right)$. Thus, high apportionment entropy figures denote great uncertainty and a uniform distribution of total flow over the individual months of the year, while low entropy figures imply lower uncertainty, and hence a strong concentration of flow in a short period of time. Unlike the entropy of the flow volume $\left(E_{H}\right)$, taking on a single value for the entire data set, the entropy of the flow distribution over time $\left(E_{R}\right)$ was calculated for each year, and its value representative of the given river gauging station was obtained by averaging over the annual figures. The notion of entropy can be applied in an analogous way to an average flow regime described by the Pardè coefficients of monthly flow. By treating the ratio of mean monthly flow to mean annual flow (Pardè coefficient) as probability $p_{i^{\prime}}$ a quantitative measure is obtained of the uniformity of the flow regime - a new index of the flow regime classification.

\subsection{Entropy of flow maxima and minima}

Information entropy was also employed to assess the uncertainty of the occurrence of maxi- mum and minimum flows in a specified period. In this way two measures were obtained of the stability of the flow regime features of the rivers under study as expressed in quantitative terms by the entropies of the occurrence of such features as their maximum and minimum monthly flows. The entropy of flow maxima $\left(E_{\max }\right)$ and minima $\left(E_{\text {min }}\right)$ was calculated in the following stages:

- the month was chosen in which a maximum or a minimum flow appeared in each year of the period 1951-1990,

- the probability of the occurrence of maximum or minimum flows in a given month was calculated from the formula:

$$
p_{\max _{i}} \text { or } p_{\min _{i}}=\frac{s_{i}}{N} \quad i=1,2 \ldots 12
$$

where $s_{i}$ is the number of occurrences of a maximum or a minimum flow in the $i$-th month and $N$ is the number of observation years, and

- the stability of the flow regime features (of a maximum or a minimum monthly flow) was determined with the help of information entropy from the formulae:

$$
\begin{aligned}
& E_{\text {max }}=-\sum_{i=1}^{12} p_{\max _{i}} \log _{2} p_{\max _{i}} \\
& E_{\text {min }}=-\sum_{i=1}^{12} p_{\text {min }_{i}} \log _{2} p_{\text {min }_{i}}
\end{aligned}
$$

The maximum $\left(E_{\max }\right)$ or minimum value $\left(E_{\min }\right)$ is attained when maximum or minimum monthly flows in the individual months of the year occur with an equal probability. Since higher entropy figures mean a lower frequency of observation of this characteristic of the river flow, entropy can be treated as a measure of the instability of the flow regime features expressed through the month in which the maximum or the minimum flow occurs.

\subsection{Study of local spatial associations}

The study of local spatial associations was conducted on the basis of Local Indicators of Spatial Association (LISA). Proposed by Anselin (1995), 
they include Moran's local $I_{i}$ statistic and Geary's local $C_{i}$ statistic which allow the identification of so-called hot spots, or areas of high values of a variable examined, surrounded by areas where is assumes lower values. Also possible is an interpretation of outliers, or areas with especially low values of the variable surrounded by regions of its high values, or vice versa. Local statistics can also indicate areas of deviations from the global spatial autocorrelation.

In the present paper use was made of Moran's local statistic, formulated as follows:

$$
I_{i}=z_{i} \sum_{j=1}^{n} w_{j} z_{j}
$$

where $z_{i}$ and $z_{j}$ are deviations from the mean, $w_{i j}$ is the weight of associations between the units $i$ and $j$, and $n$ is the number of units.

Moran's local statistic has an approximately normal distribution and is proportional to its global counterpart (Anselin 1995). It is interpreted as an index of local instability. Hence one can check if a given region $i$ is surrounded by regions with similar or different values of a variable as compared with the random distribution of those values in space. Units with statistically significant values of $I_{i}$ make it possible to identify clusters with low or high values of the variable.

With the help of LISA analysis it is possible to construct a map of local spatial clusters. Four types of clusters can be distinguished: high-high $(\mathrm{HH})$, of units with high values of the variable in question surrounded by units with high values too, low-low (LL), of units with low values surrounded by similar neighbours, as well as lowhigh (LH) and high-low (HL), of units clearly standing out from their surroundings.

\section{Results}

The uncertainty of the volume of monthly flows of rivers in the gauging stations under analysis is expressed by the flow volume entropy $\left(E_{H}\right)$; its basic statistics are presented in Table 1.

The entropy ranges from 0.24 to 3.74 bits. The lowest values, under 1.5 bits, indicating the highest ordering of the monthly flows and the highest certainty of their occurrence, are observed on rivers in an LL cluster in two regions of Europe
(Fig. 2). The first extends from southern Sweden and Denmark in the west, through eastern Germany, Poland (with the exception of its southern part), Belarus, Ukraine and the lower part of the Danube river system, to southern Russia. In Russia it embraces rivers of a broad zone from the Central Russian Upland in the west, through the Oka-Don Lowland and Volga Upland to the Caspian Lowland and Obshchy Syrt in the east. The other region includes the rivers of the Finnish Lakeland. In turn, the highest entropy of monthly flows, over 2.5 bits (an HH cluster), hence the least ordered monthly flows and the highest uncertainty of their magnitude, is characteristic of rivers of several regions. In Scandinavia those are streams of the Scandinavian Mountains; in the west of Europe, of Iceland, Ireland and Great Britain (Scotland and northern England), as well as Alpine, Caucasian and Pyrenean rivers and those in the north-western part of the Iberian Peninsula. The remaining streams display average figures of monthly flow entropy, and their profiles do not show any statistically significant local autocorrelation.

The entropy of the distribution (apportionment) of monthly flows over the year $\left(E_{R}\right)$ attains values from 0 to $\log _{2} 12=3.58$ bits. This type of entropy is expressed in per cent, assuming its maximum of 3.58 bits to be $100 \%$. Its values were calculated for each river and each year of the study period 1951-1990, and then, by averaging over the annual figures, entropies were calculated for the period as a whole.

The spatial variability of the entropy of flow distribution over time shows the rivers of the European part of Russia to be clearly distinct in this respect, since their entropy figures are the lowest - from $50 \%$ to $80 \%$ (Fig. 3). An exception is the area adjacent to Finland with the Kola Peninsula and the zone between the Black and Caspian Seas, where the entropy of the flow distribution attains much higher values. Low entropies are also characteristic of rivers in northern Norway and the western Iberian Peninsula $\left(E_{R}<80 \%\right)$; their gauging stations display a statistically significant similarity (LL clusters). A low apportionment entropy is indicative of an uneven flow distribution over time involving a strong flow concentration in a short interval of the year, often a few months. In turn, the most equalised flows over the year, as 
Table 1. Basic statistics of the analysed flow entropies.

\begin{tabular}{|l|c|c|c|c|c|}
\hline \multicolumn{1}{|c|}{ Entropy } & Min. & Mean & Max. & Standard deviation & $\begin{array}{c}\text { Variation coeffi- } \\
\text { S } \\
\text { cient } \\
\text { Cv }\end{array}$ \\
\hline $\mathrm{E}_{\mathrm{H}}[\mathrm{bit}]$ & 0.239 & 1.695 & 3.741 & 0.721 & 0.425 \\
\hline $\mathrm{E}_{\mathrm{R}}[\%]$ & 63.0 & 87.9 & 99.6 & 7.9 & 0.090 \\
\hline $\mathrm{E}_{\text {max }}[\%]$ & 0.0 & 51.3 & 92.3 & 24.3 & 0.474 \\
\hline $\mathrm{E}_{\min }[\%]$ & 18.5 & 65.3 & 91.0 & 14.6 & 0.223 \\
\hline
\end{tabular}

manifested by high entropy figures $\left(E_{R}>95 \%\right)-$ an $\mathrm{HH}$ cluster - are characteristic of rivers in the extensive west-central area of the continent, from northern Poland through Germany to the Rhine in the west and the Alps in the south. Also rivers of the Danube system, the lakeland rivers of central Finland and those of western Iceland stand out at the scale of the continent for their uniform distribution of monthly flows over the year.

The theory of entropy was also employed to assess the stability of the dates of occurrence of the maximum and minimum monthly flows. When a maximum (or minimum) mean monthly flow only occurs in one and the same month, entropy attains the lowest value equal to zero. Thus, a low entropy means great stability of the date of occurrence of the studied regime characteristic (a maximum or a minimum flow). Entropy increases, and hence so does the instability of the date of the maximum or minimum flow, when the frequency of occurrence of those flows tends to spread evenly over the individual months of the year. As in the case of the apportionment entropy, the entropy of maximum and minimum flows is expressed in per cent, and their basic characteristics are listed in Table 1.

The map of isoentropes of maximum monthly flows clearly shows areas where this feature of the flow regime is the most stable. Outstanding here are the rivers of northern and eastern Europe (Fig. 4). The entropy of the maximum monthly flow drops to the lowest values, under $40 \%$, in the case of streams of the central and northern parts of the Scandinavian Peninsula and most Russian rivers. It is only among the latter that there are some for which $E_{\max }=0$, i.e. in all the years of the study period the maximum monthly flow fell on the same month. Those are four rivers: the Dnieper (Dorogobuzh), Desna (Bryansk), Khopior (Balashov), and Vorona (Chutanovka) - an LL cluster. High stability of maximum monthly flow is only also displayed by Alpine rivers $\left(E_{\max }<40 \%\right)$ - an LH cluster. The regularity of occurrence of maximum monthly flows is markedly lower for the rivers of western, central and southern Europe. Those with the least stable dates of this feature of the flow regime $\left(E_{\max }>70 \%\right)$ are situated in a wide belt extending from southern France across central Germany, southern Scandinavia (the rivers of Jutland and southern Sweden) and Poland to western Ukraine. Maximum monthly flows show low stability also on the Apennine and Balkan rivers as well as those of northern England and Scotland (an HH cluster).

The entropies of minimum monthly flows attain values from $18.5 \%$ to $93.4 \%$ and do not show such a marked heterogeneity as those of maximum flows (Table 1). Also the mean value $E_{\text {min }}$ is clearly higher $(67.5 \%)$, which indicates a lower stability of this feature of the flow regime of the rivers under study. The date of occurrence of a minimum monthly flow is stable for the rivers of both northern and southern Europe. It is the most regular on the rivers of northern Russia $\left(E_{\min }<40 \%\right)$, the central and northern parts of the Scandinavian Peninsula, and in the south of the continent, on the rivers in the western parts of the Balkan and Iberian Peninsulas, and in the south of the Apennine Peninsula $\left(E_{\min }<50 \%\right)$ - an LL cluster (Fig. 5). Strongly unstable dates $\left(E_{\min }\right.$ $>80 \%$ ) are recorded on the rivers of central and east-central Europe, from the Weser basin in the west, through the Elbe, Oder, central Vistula and Dnieper systems, to rivers in the upper reaches of the Oka and Don basins in the east - an $\mathrm{HH}$ cluster.

\section{Conclusions}

To quantify the uncertainty of features of the flow regime of rivers in Europe, use was made of measures based on Shannon's information entropy theory (1948). Four measures were proposed that allow an assessment of the uncertainty of those features: the entropy of the magnitude of 


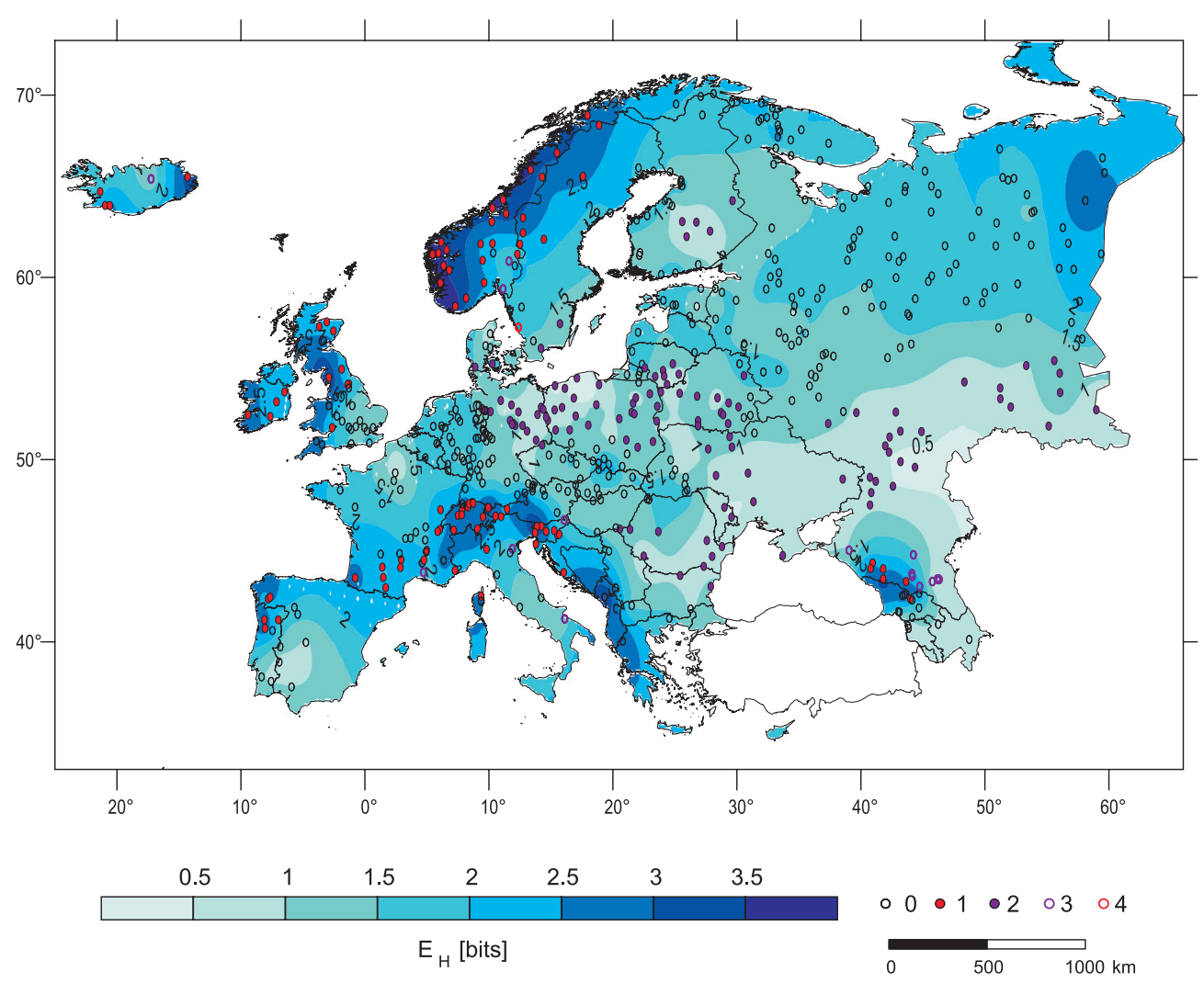

Fig. 2. Isoentropes of monthly flows and the results of analysis of local spatial associations. Explanations: 0 - statistically insignificant clusters, 1 - HH clusters, 2 - LL clusters, 3 - LH clusters, 4 - HL clusters.

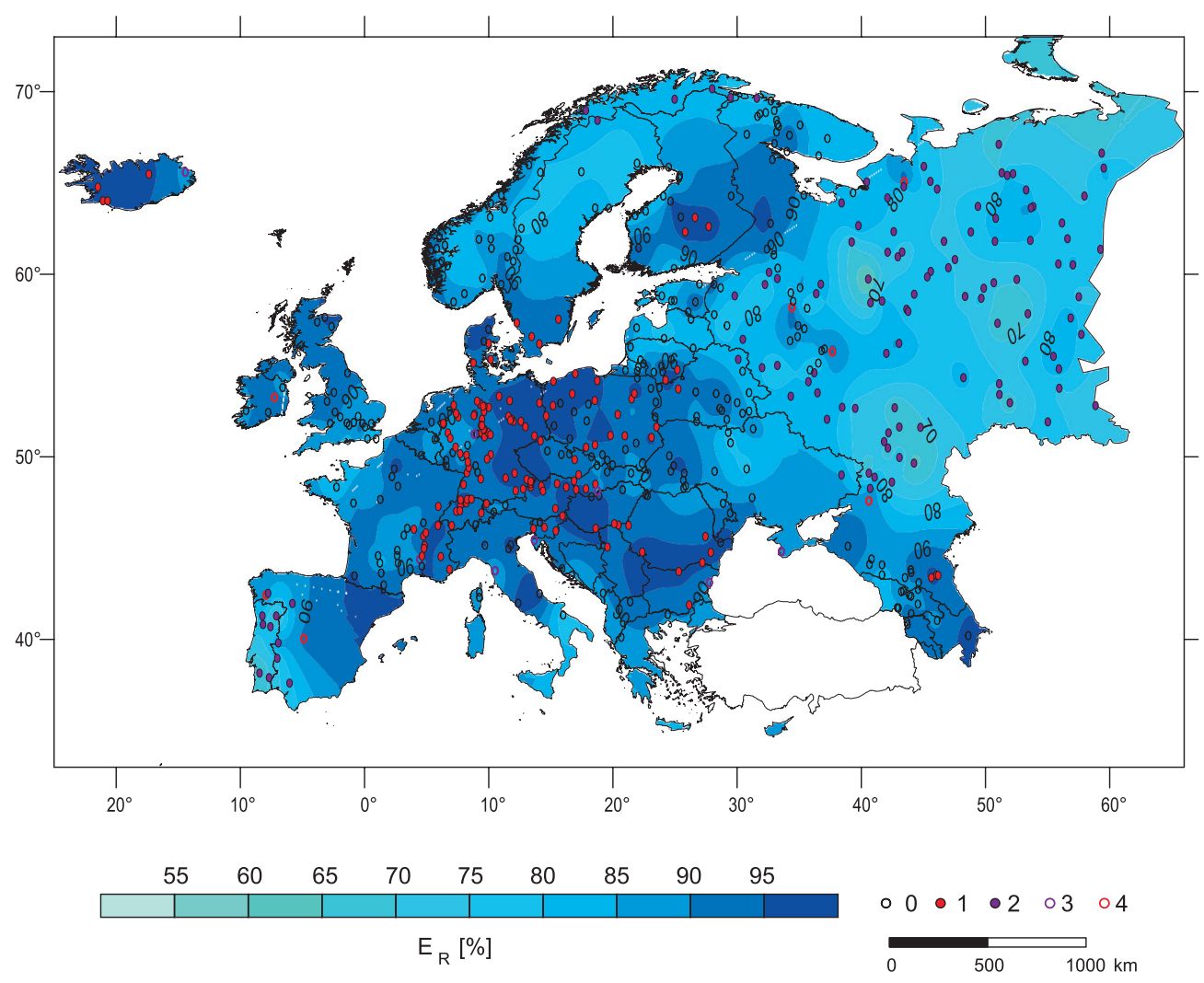

Fig. 3. Isoentropes of the distribution of monthly flows over a year and the results of analysis of local spatial associations. Explanations: 0 - statistically insignificant clusters, 1 - HH clusters, 2 - LL clusters, 3 - LH clusters, 4 - HL clusters. 


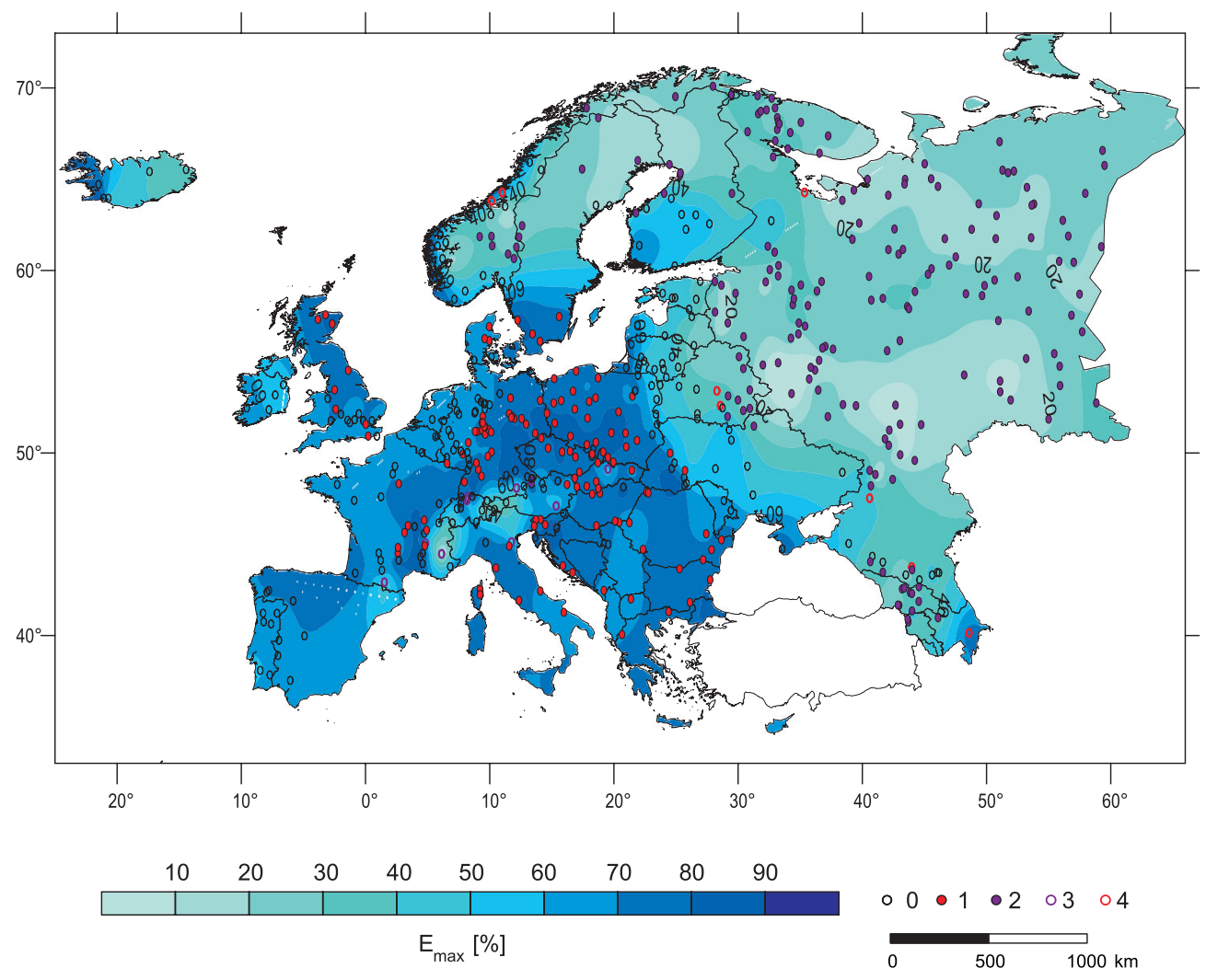

Fig. 4. Isoentropes of maximum monthly flows and the results of analysis of local spatial associations. Explanations: 0 - statistically insignificant clusters, 1 - HH clusters, 2 - LL clusters, 3 - LH clusters, 4 - HL clusters.

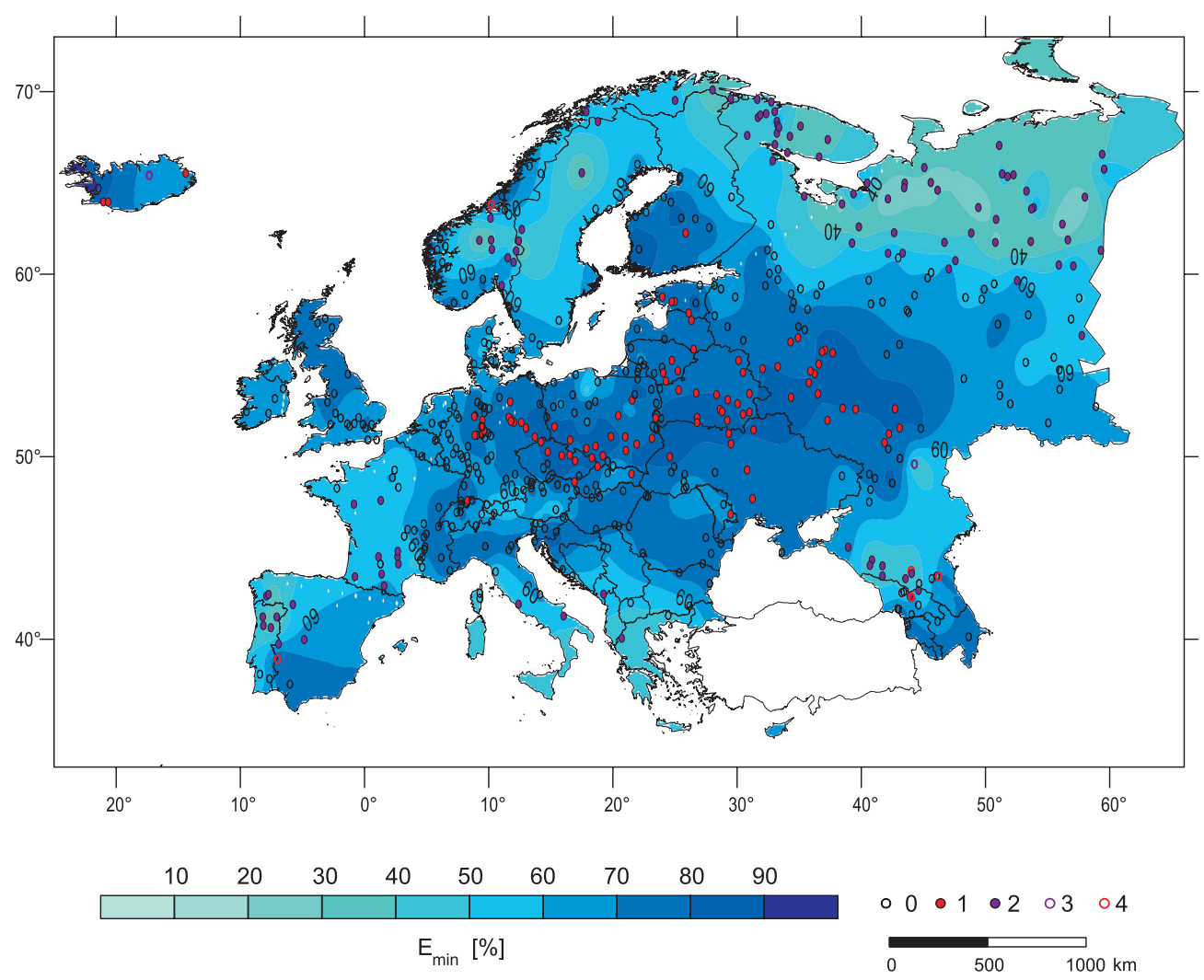

Fig. 5. Isoentropes of minimum monthly flows and the results of analysis of local spatial associations. Explanation: 0 - statistically insignificant clusters, 1 - HH clusters, 2 - LL clusters, 3 - LH clusters, 4 - HL clusters. 
monthly flows, the entropy of the distribution of monthly flows over time, and the entropy of a maximum and a minimum mean monthly flow. In turn, to identify the spatial heterogeneity of rivers in terms of the uncertainty of the flow regime features analysed, local indicators of spatial associations were employed. The application of LISA, based on Moran's local $I_{i}$ statistic, allowed a typology of rivers based on the type and statistical significance of those spatial associations. In this way, patterns of the spatial relationships of the flow regime characteristics of rivers were identified from the point of view of their uncertainty.

The entropy of monthly flow volume increases with an increase in the flow volume, which means that the predictability and certainty of the flow decrease. The most certain and predictable magnitudes of monthly flows are observed on the rivers of a belt extending from eastern Germany in the west to the Obshchy Syrt in Russia in the east, and from the parallel of latitude $55^{\circ} \mathrm{N}$ in the north to the Danube drainage basin in the south, as well as on the rivers of the Finnish Lakeland. In turn, the highest entropy, and hence the highest uncertainty and low predictability of monthly flow volumes, is characteristic of mountain rivers - Alpine, Caucasian, Pyrenean and Scandinavian, as well as Icelandic and British rivers (in Scotland, Ireland and northern England) in the west of Europe and those of north-western part of the Pyrenean Peninsula.

Uneven flow distributions over time and a strong concentration of flow in a short part of the year, often within 1-2 months, are characteristic of the rivers in the European part of Russia, northern Norway and the western part of the Iberian Peninsula. In turn, the most equalised monthly flows over the year can be observed on the rivers in the expansive west-central area of the continent, from northern Poland to the Rhine in the west of Germany and the Alpine Foreland in the south. A uniform distribution of monthly flows over the year at a scale of the continent is also displayed by rivers of the Danube system, as well as those of central Finland and western Iceland.

The month of a maximum monthly flow is the most certain and stable on rivers of northern and eastern Europe, especially in the central and northern parts of the Scandinavian Peninsula, a majority of Russian rivers, and Caucasian ones $\left(E_{\max }<40 \%\right)$. This month is the least regular $\left(E_{\max }\right.$ $>70 \%$ ) on rivers of the extensive area from England and Scotland in the west to the Bug and Dniester basins in the east, and from southern France and the Apennine and Balkan Peninsulas in the south to southern Scandinavia in the north of the continent. An exception is the Alpine rivers displaying a markedly higher certainty of occurrence of maximum monthly flows.

Rivers showing the most certain dates of minimum monthly flows occur both in northern Europe (northern Russia, central and northern parts of the Scandinavian Peninsula) and in the south the continent. In turn, the least predictable month of minimum monthly flows are characteristic of rivers of east-central Europe, from the Weser basin in the west to those of the Don system in the east.

In the paper, a method of analysis of the certainty and stability of features of the river flow regime was proposed and applied successfully. In the procedure of delimitation of areas with a similar behaviour of flow regime features, patterns of spatial associations of those of features were identified in terms of their uncertainty. In this way a typology of rivers was obtained based on the kind and statistical significance of those spatial associations. The results clearly correspond with Lvovich's (1979) and Pardè's (1957) classical methods of river regime classification, and the proposed measures of assessment of the uncertainty of features of the flow regime derived from Shannon's information entropy theory proved an interesting research tool allowing its broader characterisation. This methodological approach makes it also possible to detect a transformation in the flow regime features under the influence of changes in hydrometeorological elements brought about by human activity.

\section{References}

Alexandersson H., 1986. A homogeneity test applied to precipitation data. J. Clim., 6: 661-675.

Amorocho J. \& Espildora B., 1973. Entropy in the assessment of uncertainty in hydrologic systems and models. Water Resour. Res., 9(6): 1511-1522. 
ANSELIN L., 1995. Local Indicators of Spatial Association LISA. Geographical Analysis, 27(2): 93-115.

ArNelL N.W., 1999a. The effect of climate change on hydrological regimes in Europe: a continental perspective. Global Environmental Change, 9: 5-23.

ArNell N.W., 1999b. Assessment of the impacts of climate variability and change on the hydrology of Europe. In: van Dam, J.C. (ed) Impacts of Climate Change and Climate Variability on Hydrological Regimes. UNESCO, International Hydrology Series, Cambridge University Press, Cambridge, United Kingdom and New York, NY, USA, 52-66.

Barberis C., Molnar P., Claps P. \& Burlando P., 2003. Hydrologic similarity of river basins through regime stability. Dipartimento Di Idraulica, Trasporti ed Infrastrutture Civili, Politecnico Di Torino.

Bower D., Hannah D.M. \& McGregor G.R., 2004. Techniques for assessing the climatic sensitivity of river flow regimes. Hydrol. Process., 18: 2515-2543.

CHAPMAN T.G., 1986. Entropy as a measure of hydrologic data uncertainty and model performance. J. Hydrol., 85(1-2): 111-126.

Dalezios N.R. \& Tyraskis P.A., 1989. Maximum entropy spectra for regional precipitation analysis and forecasting. $J$. Hydrol., 109(1-2): 25-42.

Gutry-Korycka M. \& RotnicKa J., 1998. The hydrological regime of rivers in the light of scenarios of global climatic change, Geographia Polonica, Papers on Global Change, 71: 61-78.

Kagan A.M., Linnik Yu.V. \& RaO C.R., 1973. Characterization Problems in Mathematical Statistics. Wiley, New York, 408-410.

KaWachi T., Maruyama T. \& Singh V.P., 2001. Rainfall entropy for delineation of water resources zones in Japan. J. Hydrol., 246: 36-44.

KoutsoYiAnNis D., 2005. Uncertainty, entropy, scaling and hydrological stochastics, 1, Marginal distributional properties of hydrological processes and state scaling. Hydrol. Sci. J., 50(3): 381-404.

KRASOVSKAIA I., 1995. Quantification of the stability of river flow regimes, Hydrol. Sci. J., 40(5): 587-598.

KrasovsKaIA I., 1996. Sensitivity of the stability of river flow regimes to small fluctuations in temperature, Hydrol. Sci. J., 41(2): 251-264.

KRASOVSKAIA I., 1997. Entropy-based grouping of river flow regimes. J. Hydrol., 202(1-4): 173-191.

Krasovskaia I. \& GotTschalK L., 1992. Stability of river flow regimes. Nordic Hydrol., 23: 137-154.

Krasovskaia I., Gottschalk L. \& Kundzewicz Z.W., 1999. Dimensionality of Scandinavian river flow regimes. Hydrol. Sci. J., 44(5): 705-723.
Krasovskaia I. \& S $Æ$ Lthun N.R., 1997. Sensitivity of the stability of Scandinavian river flow regimes to a predicted temperature rise, Hydrol. Sci. J., 42(5): 693-711.

KRSTANOVIC P.F. \& SingH V.P., 1992. Transfer of information in monthly rainfall series of San Jose, California. In: Singh V.P. \& Fiorentino M. (eds) Entropy and Energy Dissipation in Water Resources. Kluwer Academic Publishers, Netherlands, 155-173.

Lvovich M.I., 1979. World water resources and their future. (In Polish). PWN, Warszawa.

MARUYAMA T. \& KAWACHI T., 1998. Evaluation of rainfall characteristics using entropy. Journal of Rainwater Catchment Systems, 4(1): 7-10.

Maruyama T., Kawachi T. \& Singh V.P., 2005. Entropy-based assessment and clustering of potential water resources availability. J. Hydrol., 309(1-4): 104-113.

Middelkoop H., DaAmen K., Gellens D., Grabs W., KwadijK J.C.J., Lang H., Parmet B.W.A.H., Schädler B., Schulla J. \& WILKE K., 2001. Impact of climate change on hydrological regimes and water resources management in the Rhine basin. Climatic Change, 49(1-2): 105-128.

PARDÉ M., 1947. Fleuves et rivières. Paris.

SHANnON C.E., 1948. A mathematical theory of communication. Bell System Technical Journal, 27: 379-423.

Shorthouse C. \& Arnell N., 1999. The effects of climatic variability on spatial characteristics of European river flows. Physics and Chemistry of the Earth (B), 24(1-2): 7-13.

SingH V.P., 1997. The use of entropy in hydrology and water resources. Hydrol. Process., 11: 587-626.

Sonuga J.O., 1972. Principle of maximum entropy in hydrologic frequency analysis. J. Hydrol., 17: 177-191.

SonUGA J.O., 1976. Entropy principle applied to the rainfall-runoff process. J. Hydrol., 30: 81-94.

WestmacotT J.R. \& Burn D.H., 1997. Climate change effects on the hydrologic regime within the Churchill-Nelson River Basin. J. Hydrol., 202(1-4): 263-279.

Wilson D., Hannah D.M. \& McGregor G.R, 2012. A large scale hydroclimatological perspective on western European river flow regimes. doi:10.2166/nh.2012.201

WRZESIŃSKI D., 2008. Typology of spatial patterns seasonality in European rivers flow regime. Quaestiones Geographicae, 27A/1: 87-98.

WrZESIŃSKI D., 2010. Spatial differentiation of the stability of the flow regime of European rivers. Bogucki Wydawnictwo Naukowe, Poznań, in Polish.

WrZESIŃSKI D. \& PALUSZKIEWICZ R., 2011. Spatial differences in the impact of the North Atlantic Oscillation on the flow of rivers in Europe. Hydrol. Res., 42(1): 30-39 